\title{
GENOMETRIX
}

April 20, 1998

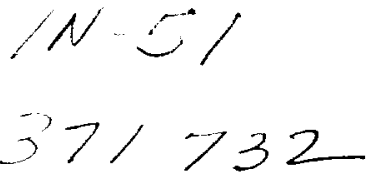

Ms. Loren Kruger

Contract Specialist

NASA Goddard Space Flight Center

Code 216

Greenbelt, MD 20771

Re: Contract NAS5-97183, Basic Contract

Dear Loren:

Enclosed is your copy of the FINAL Progress Report \#10 on the above referenced contract for the month of February 1998.

Sincerely,

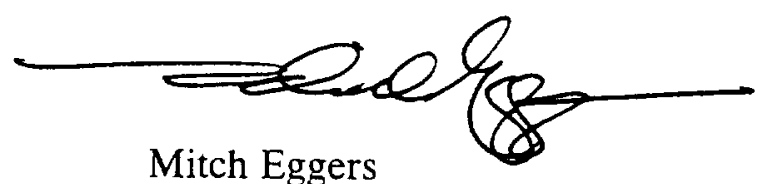

President

$\mathrm{ME} / \mathrm{jr}$

Enclosures

cc: Mr. Guy Fogleman, COTR, HQ Code UL (w/report)

Publication and Graphic Services Section, Code 253.1 (w/report)

Center for AeroSpace Information (w/report-2)

Maria McNamara, Defense Contract Management Command 


\section{An Advanced Approach \\ to \\ Simultaneous Monitoring \\ of \\ Multiple Bacteria in Space}

Final Report

March 1998

Submitted to

National Aeronautics and Space Administration

Life and Biomedical Sciences and Applications Division

Contract Number NAS5-97183

Genometrix Inc./Baylor College of Medicine/University of Houston

Principal Investigator: Mitch Eggers

Proprietary Note

This document contains information proprietary to Genometrix Incorporated and is furnished for the sole purpose of supplying the recipient with the needed information for the evaluation of the progress. Its contents should not be disclosed or reproduced, in any manner, by the recipient without the written consent of Genometrix incorporated. 


\section{TABLE OF CONTENTS}

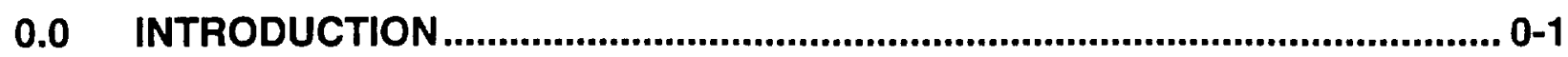

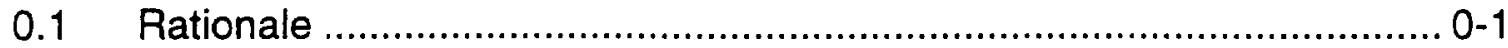

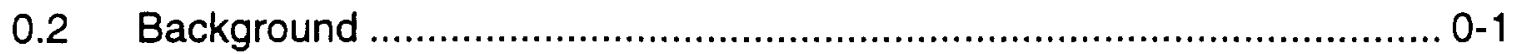

1.0 DNA/RNA SELECTION AND PREPARATION........................................... 1-1

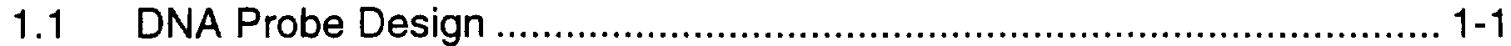

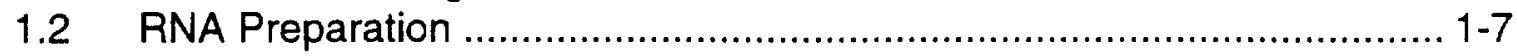

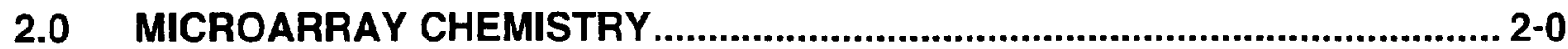

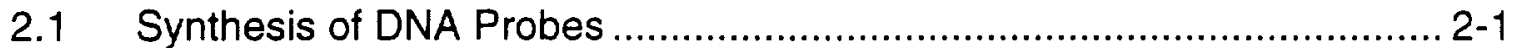

2.2 DNA Probe Attachment Chemistry ................................................ 2-1

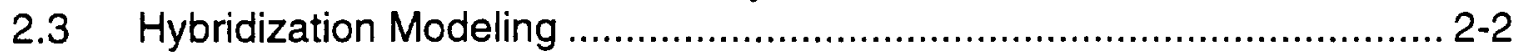

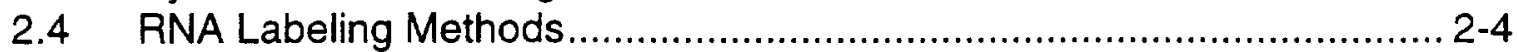

INSTRUMENTATION.......................................................................................... 3-0

3.1 Microarray Printer ….............................................................................

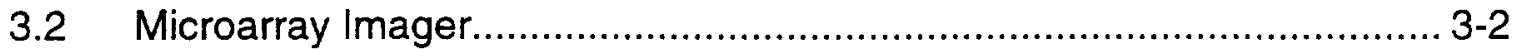

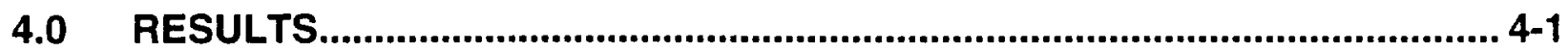

4.1 Sample Collection/rRNA Isolation............................................... 4-1

4.2 DNA Probe Selection.................................................................. 4-2

4.3 Microarray Fabrication ................................................................... 4-3

4.4 Microarray Hybridization ............................................................... 4-4

4.5 Microarray Labeling ..................................................................... 4-4

4.6 Microorganism Detection .............................................................. 4-5

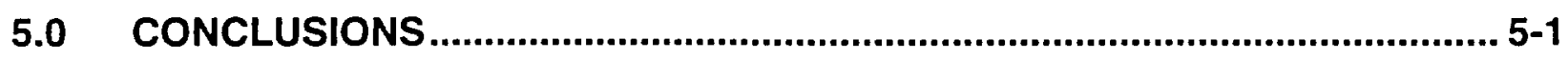

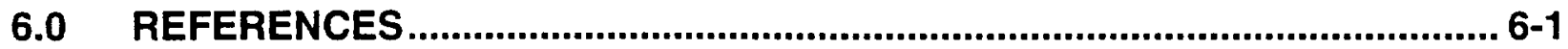




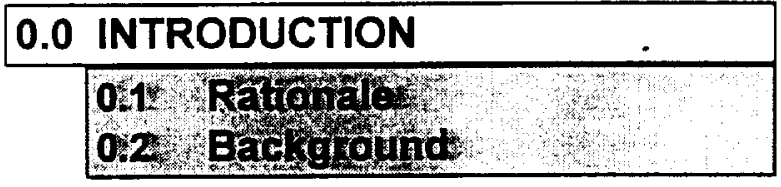

\subsection{Rationale}

Crew health is a dominant issue in manned space flight. Microbiological concerns have repeatedly emerged as determinants of flight readiness. For example, in at least one case, suspected contamination of the potable water supply nearly forced a launch delay. In another instance, a crew member's urinary tract infection nearly led to early termination of the mission, partly because of the difficulty of accurately diagnosing the nature of the infection inflight. Microbial problems are an increasing concern with the trend towards longer-duration missions. It is essential to the success of such missions that systems deliver acceptable quality of air and water during the anticipated lifetime of the spacecraft.

As mission duration and re-supply intervals increase, it will be necessary to rely on advanced life support systems which incorporate both biological and physicalchemical recycling methods for air and water as well as provide food for the crew. It therefore is necessary to develop realtime, robust, in-flight monitoring procedures. In the case of water these procedures should be sensitive enough to detect less than 100 CFU (colony forming units) of bacteria per 100 milliliters. It would also be desirable if the monitoring system could be readily "reprogrammed" to identify specific pathogens if an in-flight incident were to occur.
The overall goal of this project was to develop a microchip-based bacterial monitoring system for detecting and quantifying multiple microorganisms which could be readily miniaturized for in-flight application.

\subsection{Background}

Traditional methods for identifying and enumerating bacteria are slow and usually overlook numerous organisms because they require cultivation, and also such methods are highly incompatible with the space environment. The development of more effective microbial identification technologies has been a widely sought goal for the past decade. Molecular techniques involving nucleic acids have been particularly promising. The small subunit ribosomal RNAs (16S rRNA in prokaryotes and $18 \mathrm{~S}$ rRNA in eukaryotes) are an especially promising target for DNA probes because

(1) it occurs in as many as 10,000 copies per bacterial cell, making a preliminary PCR amplification step unnecessary

(2) possesses conserved and hypervariable regions.

This pattern of sequence conservation makes it possible to design RNA/DNA hybridization probes that can distinguish individual organisms, or groupings of related organisms (Amann et al., 1995; Jurtshuk et al., 1992; \& others). Practical diagnostic kits based on this technology (e.g. for Legionella and Chlamydia) have been successfully introduced into the clinical market. 
Specifically the multidisciplinary project involved three components; biology, chemistry, and engineering. The development in each of these program components are presented in the following sections entitled, (1) DNA/RNA Selection and Preparation, (2) Microarray Chemistry and (3) Instrumentation. Feasibility of the microarray-based microbial analyzer was established with "live" water samples taken from the Lunar-Mars Life Support Test Project at JSC. The overall performance of the microbial analyzer exercised on real water samples is described in the Results section. Finally, conclusions are drawn from the project and recommendations provided for additional developments in support of a portable, in-flight microbial analyzer. 


\subsection{DNA/RNA SELECTION AND PREPARATION \\ 14t DNA Prober Design \\ 1.2 RNAPreparation}

\subsection{DNA Probe Design}

Initially several probe targets which would be expected to readily differentiate Escherichia coli 16S rRNA from Vibrio proteolyticus $16 \mathrm{~S}$ rRNA in a mixture of both RNAs were designed. Preliminary experiments conducted by the chemistry group suggested that a sandwich assay utilizing both a capture probe and a detector probe would be a particularly promising format. In this scheme a surface capture probe is used to selectively acquire the target rRNA from a total RNA preparation. The detector probe provides a labeling group and assists in the denaturation of the target molecule by disrupting the secondary structure of the target rRNA in the region where it binds to the capture probe. The detector probe should in no instance select against the rRNA of target organisms.

The logical next step was to develop prototype hybridization arrays for detecting several organisms. To insure that this prototype system also has practical utility, additional discussions with the NASA microbiology group were held at Lyndon B. Johnson Space Center to develop a consensus of appropriate organisms to detect. It was concluded that a first generation water quality monitoring system that could simultaneously monitor six microbial groups would be of considerable value. The proposed prototype would: (1) measure total bacterial levels; (2) determine the level of enterics as indicator organisms of fecal contamination; (3) contain specific probes for $E$. coli; (4 and 5) contain genus specific probes for Enterococcus and Burkholderia; and (6) and contain probes for monitoring the presence of the species Pseudomonas aeruginosa and organisms related to it at the genus level.

Initial experiments with pairs of adjacent homologous/mismatched probes to differentiate $E$. coli from $V$. proteolyticus concluded that two mismatches between a probe and a target could be detected in a sandwich assay. All the probes designed herein were therefore required to have at least two mismatches with all the organisms selected against. Three methods were used to design probes depending on the number and nature of both sets of organisms detected and selected against.

In the first approach, sets of aligned sequences were obtained from the public Ribosomal Database Project (RDP) database (http://www.cme.msu.edu/RDP) which include the target species (or genus) and closely related organisms. These sequences were then placed into a sequence editor that allows the sequences to be discriminated according to their identity with the target species. It was then easy to visually identify sequence regions likely to distinguish the target species from other organisms (Figure 1-1). The most promising probes were then searched against the entire 16S rRNA database for spurious matches. This rapid strategy was used to identify the $E$. coli-specific probe pair (Table 1-1). 


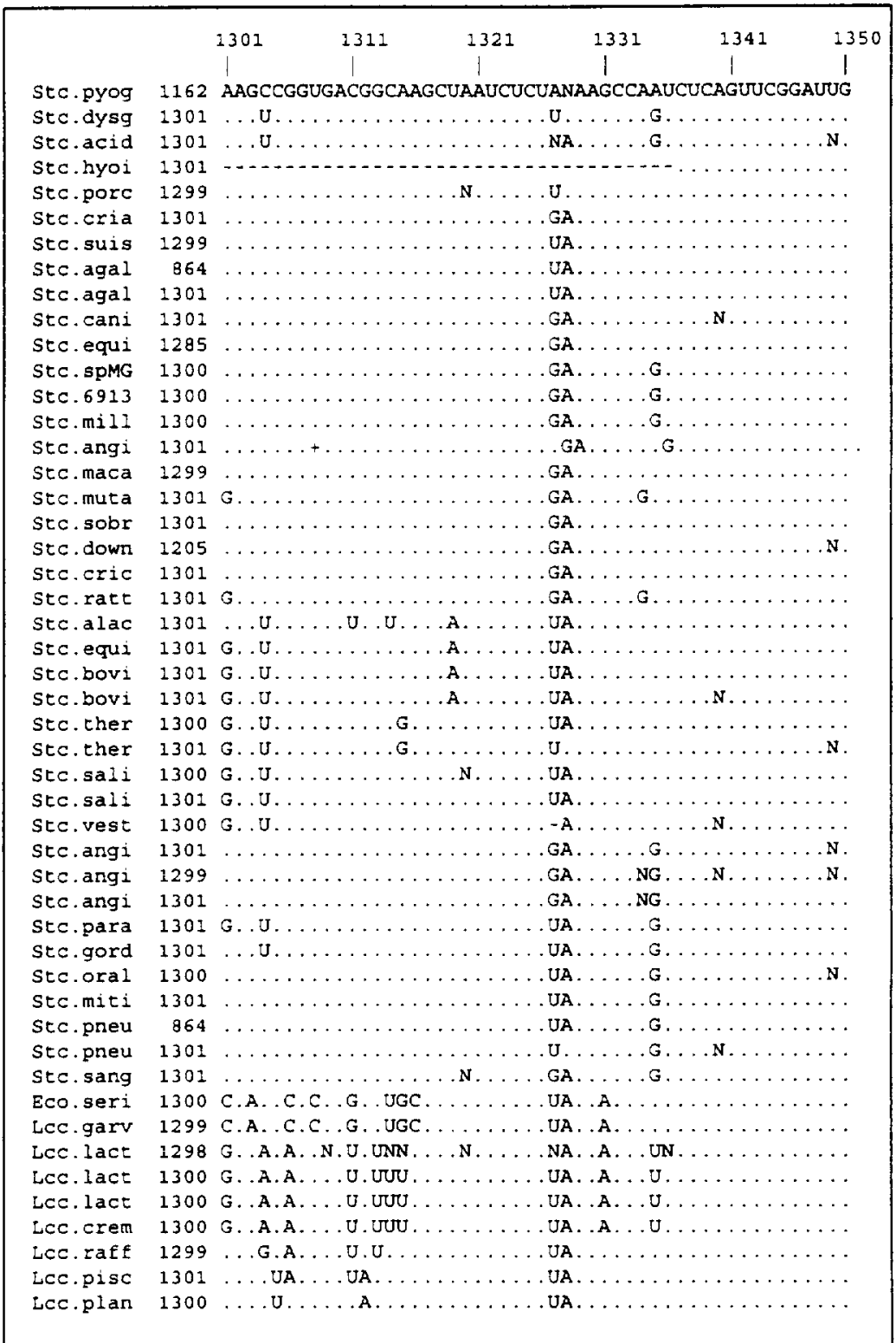

Figure 1-1. Visual of an alignment using the PrettyPrint function in GDE.

This basic strategy was unsuitable to search for probes for all Bacteria, mainly because there is sufficient variability in this data set as a whole, that no single probe of sufficient length binds to all bacteria. Hence, a search for a minimal set of capture probes that would, together, specifically detect all Bacteria (Figure 1-2) was conducted. 


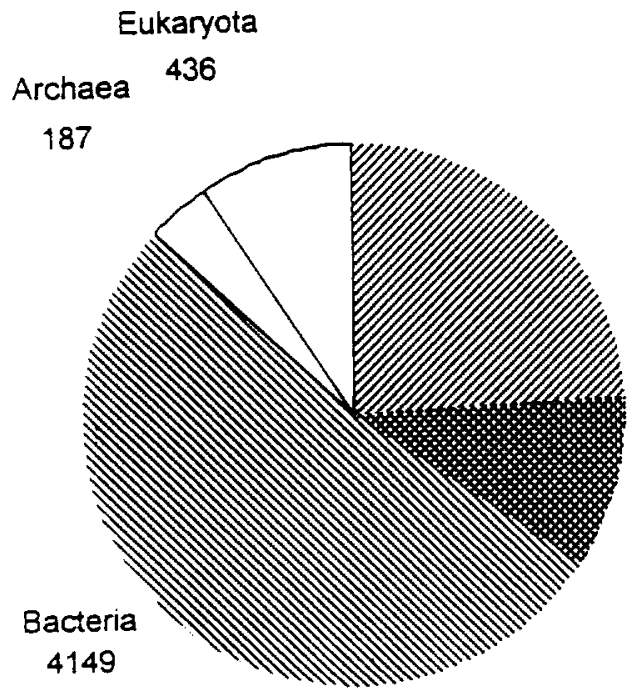

ミBacteria detected by S-D-Bact-0339-a-A-16 " Bacteria detected by S-D-Bact-0780-a-A-18

* Bacteria detected by both probes

Figure 1-2. Relative abundance of the available sequences of the three kingdoms in RDP. See Table 1-1 for the probe description.

Since eukaryotic $18 \mathrm{~S}$ rRNA is very different from prokaryotic 16S rRNA, bacterial probes were sought that would select against archaeal 16S rRNA, and later verified that they did not detect any $18 \mathrm{~S}$ rRNA. Despite the slight decrease in the number of sequences to manipulate, the number of $16 \mathrm{~S}$ rRNA sequences in the RDP database was still very large (187 Archaea and 4149 Bacteria), and a computational approach was needed to assist the search for promising probes. Two programs, find probe and most_mismatch were designed and coded for this purpose.

A reference organism, for which complete 16S rRNA sequence data is available, was first chosen (e.g., in the case of total Bacteria, or for the enteric probes, $E$. coli). Then, all 13-mers (patterns) from the reference sequence different by at least two bases from all archaeal sequences were identified with find probe (Figure 1-3). The choice of 13-mers was based on the fact that this is the minimal probe length that could be used in hybridization experiments. The patterns were then sorted by increasing number of bacterial sequences in which they were found, using most mismatch (Figure 1-4). The pattern found in the most bacterial sequences was kept as a possible probe target, and the bacterial sequences in which it was not found were extracted in a new file. The file of patterns was sorted again with most_mismatch using this new file, and a second target region was then identified. The probe sequences for these two target regions are the complementary sequences from the targets. For each capture probe, a detector probe was chosen adjacent to the capture probes, two bases away. Most detector probes are degenerated at several positions to ensure they bind to all organisms from the target set. 


\begin{tabular}{|c|c|c|}
\hline $\begin{array}{l}\text { Reference organis } \\
\text { File of target orga } \\
\text { File of undesired } \\
\text { Maximum numbe } \\
\text { Minimum number } \\
\text { Probe lenguh: } 13 \\
\text { File name: bact.al } \\
\text { Program started o }\end{array}$ & $\begin{array}{l}\text { ns I organism } \\
\text { htains I } 40 \text { organisms } \\
\text { with the target organis } \\
\text { with the undesired org } \\
\text { and finished on } 02 / 27\end{array}$ & $1: 46: 19$ \\
\hline Probe & $\begin{array}{l}\text { Position(s) in } \\
\text { reference organisn }\end{array}$ & $\begin{array}{l}\text { Number of target } \\
\text { organisms detected }\end{array}$ \\
\hline aanuugangaguu & 1.13 & 1 \\
\hline aauugaagaguuu & 2,14 & 1 \\
\hline auugasgagunus & 3.15 & 1 \\
\hline ungaagaguuuga & 4,16 & 1 \\
\hline ugaagagnuugau & 5.17 & 1 \\
\hline gaagaguuugauc & 6,18 & 1 \\
\hline aagaguuugauca & 7.19 & 1 \\
\hline agaguuugaucau & 8.20 & । \\
\hline gaguuugnucaug & 9.21 & 1 \\
\hline aguungaucaugg & 10,22 & 1 \\
\hline uuugaucauggcu & 12.24 & 1 \\
\hline uugaucauggcuc & 13.25 & 1 \\
\hline ugaucauggcuca & 14,26 & 1 \\
\hline gaucauggaucag & 15.27 & ] \\
\hline aucauggeucage & 16.28 & 1 \\
\hline ucauggcucagaa & 17,29 & 1 \\
\hline cauggcucagauu & 18,30 & 1 \\
\hline auggcucagauug & 19,31 & I \\
\hline uggcucagauuga & 20.32 & I \\
\hline gcucagauuganc & 22,34 & I \\
\hline cucagauugaacg & 23,35 & I \\
\hline ucagauugaacge & 24,36 & 1 \\
\hline cagauugancgeu & 25.37 & 1 \\
\hline ayauugaacgcug & 26,38 & 1 \\
\hline auugaacgcuggc & 28.40 & 1 \\
\hline uugnacgeugycg & 29.41 & 1 \\
\hline gaacgeuggcgge & 31.43 & 1 \\
\hline aacgcuggcggca & 32.44 & 1 \\
\hline acgcuggeggcag & 33,45 & 1 \\
\hline cgeuggcggcagg & 34,46 & 1 \\
\hline gcuggeggcaggc & 35,47 & 1 \\
\hline uggcggcagyccu & 37,49 & 1 \\
\hline ggcggcaggccua & 38,50 & 1 \\
\hline gcggcaggccuas & 39.51 & 1 \\
\hline cggcaggccuaac & 40,52 & 1 \\
\hline ggcaggccuaaca & 41,53 & 1 \\
\hline gcaggecuaacac & 42,54 & 1 \\
\hline caggecuancaca & 43.55 & 1 \\
\hline aggccusacacau & $\$ 4,56$ & 1 \\
\hline geccuascacaug & 45.57 & 1 \\
\hline gecusacacaugc & 46.58 & 1 \\
\hline ccuancacaugca & 47,59 & 1 \\
\hline cuascacaugcas & 48.60 & 1 \\
\hline uascacaugcaag & 49,61 & 1 \\
\hline
\end{tabular}

Figure 1-3. First page of the file returned by find probe with the command line:

$>$ find_probe bact.ref bact.ref archae.pl 02 1313 bact.all
File of probes: bact. all

File of target organisms: bact. des contains $\$ 145$ organisms

Number of mismatches allowed with the target organisms: 0

File name: bact.all, sort

Program started at $11: 14: 53$ and finished at $18: 22: 28$

Probe reference organism organisms detected

\begin{tabular}{lll}
\hline cagcaguggggaa & 352.364 & 2149
\end{tabular}

$\begin{array}{lll}\text { ugugguuuakuuc } & 950.962 & 2154\end{array}$

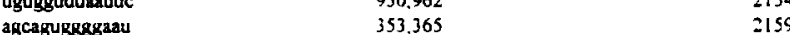

agcagugeggatu

ggcagcagugggg

augugguuvaavu

ggangguggegau

353.365

350,362
949,961

1177,1189

gaggeagcagugg $\quad 348.360$

asgcagcaguggg $\quad 349.361$

gugruuusauce $\quad 951.963$

aagcrugeggagc $\quad 767.779$

$\begin{array}{ll}\text { auacguucecggg } & 1375,1387\end{array}$

$\begin{array}{ll}\text { gggcuacacacgu } & 1220,1232\end{array}$

$\begin{array}{ll}\text { gasuacguucceg } & 1373,1385\end{array}$

aluacguuccegg 1374,1386

$\begin{array}{ll}\text { acacacgugculac } & 1225,1237\end{array}$

cacougcuacesu 1228,1240

acacgugcuacas $\quad 1227.1239$

ggaggcagcagug $\quad 347,359$

$\begin{array}{ll}\text { cacacgugcuaca } & 1226.1238 \\ \text { cgegcgcancccu } & 1103,1115\end{array}$

acgugcuacang

ugguaguccacgc

cugguaguecacg

gacuccuacygga

auguuggguuaas

cgcaacgagcgca

cegcasagagcgc

ggguuangucecr

gcaacgagcgcaa

guuggguuasgue

uuggguuaaguec

uguugggutaagu

cascgagcgcasc

acuccuscgggag

ceuncgggaggca

uccuaçsgagge

cuacgegaggcag

uacgegaggeagc

acgagcgcaaccc

1229.1241

798.810

797.809

337.349

1082.1094

1098,1110

1097,1109

1087,1099

1099,1111

1084,1096

1085, 1097

1083,1095

1100,1112

338,350

341,353

340352

342,354

343,355

a.acgagcgcaace

1101.1113

Figure 1-4. Last page of the file returned by most_mismatch with the command line:

>most_mismatch bact.all bact.des 0 bact.all.sort 
Finally, a hybrid of the previous two methods was used to design probes for most genera of Table 1-1. All the 13-mers of a reference sequence different by at least two bases with all other bacteria were identified using find probe. At this point, the sequences of the group are visualized in a sequence editor, e.g. GDE (Genetic Data Environment) and the 13-mers common to the most sequences were further considered and when possible extended to greater
In some cases the target group is actually comprised of two or more major clusters. Thus, for example, in the case of Streptococcus, there are two clusters, "true Streptococci" and Lactococci. In this case, after identifying the first target region (for "true Streptococci"), a Lactococcus was chosen as a new reference organism and the procedure was repeated for the Lactococcus group. lengths.

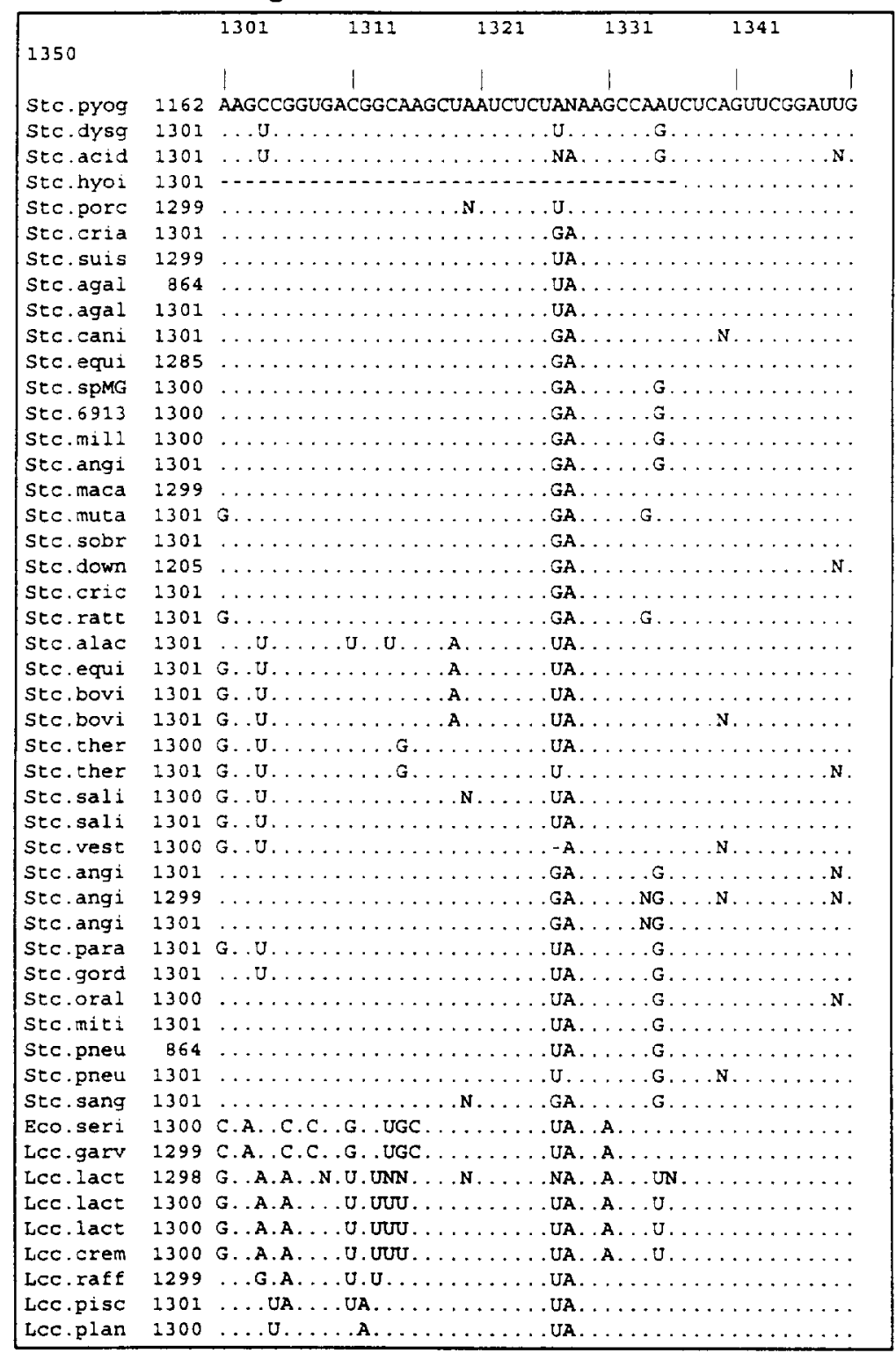

Figure 1-5. Streptococcus alignment. Notice that a slightly degenerate probe hybridizing to the 13031326 region of $S$. pyogene would detect almost all Streptococci, but no Lactococci. 
These basic procedures were followed in order to design possible capture and detector probes for all six groupings in the prototype water quality monitoring system. The probes are shown in Table 1-1. Some of these probes have been tested in hybridization arrays as described elsewhere in this report.

Table I: Suggested probes and their specificity.

\begin{tabular}{|c|c|c|c|}
\hline Probe (5' $\rightarrow$ 3') & Capture for: & Detector for: & Comments \\
\hline $\begin{array}{l}\text { S-D-Bact-0339-a-A-16 } \\
\text { cwgechcecgtaggdg }\end{array}$ & Bacteria & & $\begin{array}{l}\text { Degenerate at } 3 \text { positions. } \geq 2 \text { mismatches } \\
\text { with all Archae } \\
\text { Misses S. paucimobilis, } X \text {. maltophilia }\end{array}$ \\
\hline $\begin{array}{l}\text { S-D-Bact-0318-a-A-17 } \\
\text { gnccgtrtytcagtncc }\end{array}$ & & Bacteria & Degenerate at 4 positions \\
\hline $\begin{array}{l}\mathrm{S}-\mathrm{D}-\mathrm{Bact}-0780-\mathrm{a}-\mathrm{A}-18 \\
\mathrm{NH}_{2} \text {-agggtatctaatcctgtt }\end{array}$ & Bacteria & & $\begin{array}{l}\geq 2 \text { mismatches with all Archae } \\
\text { Misses Staphylococci, some Burkholderiae }\end{array}$ \\
\hline $\begin{array}{l}\text { S-D-Bact-0801-a-A-17 } \\
\text { gtttasngcrtggacta }\end{array}$ & & Bacteria & Degenerate at 3 positions \\
\hline $\begin{array}{l}\mathrm{S}-\mathrm{S}-\text { E.coli-0466-a-A-17 } \\
\mathrm{NH}_{2} \text {-tcaatgagcaaaggtat }\end{array}$ & E. coli & & $\geq 4$ mismatches with others \\
\hline $\begin{array}{l}\text { S-G-Ralstonia-0631-a-A-19 } \\
\text { cgtgcagtcaccaatgcaa }\end{array}$ & Ralstonia & & $\geq 2$ mismatches with all others \\
\hline $\begin{array}{l}\text { S-G-NeisRals-0650-a-A-19 } \\
\text { yccetctgacayactckag }\end{array}$ & & $\begin{array}{l}\text { Ralstonia and } \\
\text { Neisseria }\end{array}$ & \\
\hline $\begin{array}{l}\text { S-G-Burk-0824-a-A-19 } \\
\text { gaatccccaacaactagtt- } \mathrm{NH}_{2}\end{array}$ & $\begin{array}{l}\text { Burkholderia + } \\
\text { Ralstonia }\end{array}$ & & $\geq 3$ mismatches with all others \\
\hline $\begin{array}{l}\text { S-G-Beta-0803-a-A-21 } \\
\text { rcatsgtttagggcgtggac }\end{array}$ & & Burkholderia & Degenerate at 3 positions \\
\hline $\begin{array}{l}\text { S-G-Neis-0632-a-A-17 } \\
\text { ayccagttcaraacgca }\end{array}$ & Neisseria & & $\begin{array}{l}\text { Misses Vit.setr (2), Crb.viol, lod.fluv, } \\
\text { Kin.oral, Kin.king (2) and Sim.muel }\end{array}$ \\
\hline $\begin{array}{l}\text { S-G-NeisRals-0650-a-A-19 } \\
\text { yccctctgacayactckag }\end{array}$ & & $\begin{array}{l}\text { Ralstonia and } \\
\text { Neisseria }\end{array}$ & \\
\hline $\begin{array}{l}\text { S-G-Staph-0460-a-A-17 } \\
\text { gaygtgcayagttactt }\end{array}$ & Staphylococcus & & $\geq 3$ mismatches with all others \\
\hline $\begin{array}{l}\text { S-F-Staph-0481-a-A-19 } \\
\text { ctttctgrtyagtrccgtc }\end{array}$ & & $\begin{array}{l}\text { Staphylococcus } \\
\text { group }\end{array}$ & \\
\hline $\begin{array}{l}\text { S-G-Staph-0226-a-A-22 } \\
\text { ctaatacggcgegggtccatct }\end{array}$ & $\sum_{2 \cdot}^{\text {Staphylococcus }}$ & & $\geq 2$ mismatches with all others \\
\hline $\begin{array}{l}\text { S- - 0250-a-A-19 } \\
\text { agccgttacctyaccaact }\end{array}$ & & $\begin{array}{l}\text { A bit } \\
\text { everything }\end{array}$ & \\
\hline $\begin{array}{l}\text { S-Sb -S.caseolyticus--a-A-20 } \\
\text { agcgtcagttrsagaccaga }\end{array}$ & S. caseolyticus & & \\
\hline $\begin{array}{l}\text { S-G-Pseud-0439-a-A-18 } \\
\mathrm{NH} \text {-tgecettcctcccaactt }\end{array}$ & Pseudomonas & & $\begin{array}{l}\geq 3 \text { mismatches with all others } \\
\text { misses: str. B0267, str. BO251, Ps.syring4, } \\
\text { Ps.fluore } 4 \text { (sequence data lacking) }\end{array}$ \\
\hline $\begin{array}{l}\text { S-G-Pseud-0417-a-A-22 } \\
\text { aaagtgctttacaatccgaaga }\end{array}$ & & Pseudomonas & $\begin{array}{l}\text { Only P. fluorescens strain MS } 1650 \text { is } \\
\text { undetected. }\end{array}$ \\
\hline $\begin{array}{l}\text { S-G-Strep-0994-a-A-21 } \\
\text { ctargratagcackrgtatgt }\end{array}$ & Lactococcus & & \\
\hline \multicolumn{4}{|l|}{$\begin{array}{l}\text { S-G-Strep-0972-a-A-20 } \\
\text { agacctggtaaggttgttgc }\end{array}$} \\
\hline $\begin{array}{l}\text { S-G-Strep-1264-a-A-22 } \\
\text { agagattwgcytgccgtcaccg }\end{array}$ & Streptococcus & & $\begin{array}{l}\geq 2 \text { mismatches with all organisms but } \\
\text { Streptococci. } \\
\text { Misses all lactococci. }\end{array}$ \\
\hline $\begin{array}{l}\text { S-P-Gram+-1288-a-A-20 } \\
\text { atccgaactgagayyggctt }\end{array}$ & & Gram positive & \\
\hline
\end{tabular}




\begin{tabular}{|c|c|c|}
\hline $\begin{array}{l}\text { S-S-B.cepacia-0456-a-A-17 } \\
\text { ggtgtattagagccaa }\end{array}$ & $\begin{array}{l}\text { B. cepacia + Ps: } \\
\text { cepacia }\end{array}$ & $\geq 4$ mismatches with all others \\
\hline $\begin{array}{l}\text { S-S-R.pickettii-0081-a-A-18 } \\
\text { gecatcaatcragcasgc }\end{array}$ & R. picicettii & Use in conjunction with one of the Burkholderia probes \\
\hline $\begin{array}{l}\text { S-S-B mailei-0455-a-A-21 } \\
\text { actccgggtartagccagaat }\end{array}$ & $\begin{array}{l}\text { B. pseudomallei + B. } \\
\text { mallei }\end{array}$ & $\begin{array}{l}5 \text { mismatches with R.eutrop. } \geq 6 \text { mismatches with all } \\
\text { ochers. }\end{array}$ \\
\hline $\begin{array}{l}\text { S-G-Acinetobacter-0436-A-A-j9 } \\
\text { agceuccuccucgcuuasa }\end{array}$ & Acinetobacter & \\
\hline $\begin{array}{l}\text { S-G-Alphs-4l4-a-A-20 } \\
\text { gettracanccmwanggect }\end{array}$ & Acinetobacter & $\begin{array}{l}\text { Degenerate at } 2 \text { positions } \\
\text { Misses Can.Iwof and Can. anit }\end{array}$ \\
\hline
\end{tabular}

1 this group includes: Stp. sapro3, sapro2, saprop, cohnii, caprae, equorm, haemo3, haemo2, aeroph, homini, homin3, muscae, intmed, schle3, schle2, schlei, warne2, warner, aureu4, aureu5, aureu2, aureus, haemol, ariett, capitc, capitu, capit2, sacly2, epide3, epide5, epider, lugdun, and Spi.spN26

2 this group includes: : Stp. sapro3, sapro2, saprop, cohnii, caprae, kloosi, equorm, haemo3, haemo2, carnos, auricu, auric3, muscae, sp1, intmed, schle3, schle2, schlei, pulver, sciur3, sciuri, lugdun, and Spi.spN26

- not enough sequence data was available for Stp. auric2, aureu3, saclyt, epide2, and epide4

\subsection{RNA Preparation}

Before assembling a multiple probe set, it is important to ascertain that each individual probe can distinguish its target group from most likely interfering organisms. Hence, total RNA was extracted from representative strains of the various organisms. Cultures $(50 \mathrm{ml})$ of each bacterial strain of interest were centrifuged at $4^{\circ} \mathrm{C}$ for $10 \mathrm{~min}$, and resuspended in ACE buffer (10 $\mathrm{mM}$ sodium acetate $\mathrm{pH} 5,50 \mathrm{mM} \mathrm{NaCl}, 3 \mathrm{mM}$ EDTA). The cells were lysed by adding first $20 \mu \mathrm{l}$ of $1 \mathrm{mg} / \mathrm{ml}$ lysozyme and incubating $5 \mathrm{~min}$ on ice, and then $400 \mu \mathrm{l}$ of $0.5 \mathrm{M}$ sodium acetate and $200 \mu \mathrm{l}$ of $10 \%$ SDS and incubating 10 min on ice. This was followed by a double ACE-equilibrated phenol extraction, a $\mathrm{CH}_{3} \mathrm{Cl}$ :isoamyl alcohol (24:1) extraction, and an ethanol precipitation. The pellets were resuspended in $100 \mu \mathrm{H}_{2} \mathrm{O}$ and stored at $-20^{\circ} \mathrm{C}$. This total RNA was used in hybridization experiments reported in the Results section.
A second aspect of the microbiology effort was devoted to the development of spacecraft-compatible methods of isolating nucleic acids from complex samples (soil, blood, air and waterborne particulates). Of particular interest is methods not requiring the use of toxic substances such as phenol and ethidium bromide, and/or high-speed centrifugation. These constraints eliminate essentially all conventional methods, so the present work has started fresh to lay the groundwork for new approaches.

\section{Selective Adsorption of RNA}

One of the few chemical differences between RNA and DNA which can serve as the basis of separation is the presence of the vicinal $2^{\prime}, 3^{\prime}$ cis-diol at the $3^{\prime}$ end of the RNA molecule. This feature is absent from the deoxyribose backbone of DNA, and is exploited as the basis of recognition by boronate affinity methods. Boronic acid chromatography has been used for tRNA and (ribo)nucleotide isolation since the 1970's (Moore et al., 1974; McCutchan, 1975). Several workers have subsequently 
demonstrated the application of boronic acid chromatography to separation of nucleic acids and their derivatives, and of sugars and glycosylated proteins (Ackerman et al., 1979; Benes et al., 1993; Bergold and Scouten, 1983; Bouriotis et al., 1981; Pace and Pace, 1980; Fulton, 1981). In addition, it has been demonstrated that modification of the m-aminophenylboronic acid group to confer a lower pKa on the boronic acid moiety can enhance the range of $\mathrm{pH}$ over which these adsorbents are useful (Liu et al., 1994 , 1995). We have used batch equilibrium adsorption isotherm measurement and several supporting techniques to characterize the adsorption of mixed RNAs on m-aminophenylboronic agarose under a variety of conditions.

Research indicated that the well-known affinity-enhancing influence of divalent cations depends strongly on the precise nature of the cation used, with barium being far more effective than the conventionallyused magnesium. This adsorption-promoting influence of barium is likely to arise primarily from ionic influences on the structure and rigidity of the RNA molecule, as the adsorption of ribose-based small molecules is not similarly affected. The substitution of barium for the standard magnesium counterion does not greatly promote the adsorption of DNA, implying that the effect is specific to RNA and may be useful in boronate-based RNA separations. RNA adsorption isotherms exhibit a sharp transition as a function of temperature, and this transition occurs at different temperatures with $\mathrm{Mg}^{2+}$ and $\mathrm{Ba}^{2+}$. Adsorption affinity and capacity were found to increase markedly at lower temperatures, suggestive of an enthalpically favored interaction process. The stoichiometric displacement parameter, $\mathrm{Z}$, in $\mathrm{Ba}^{2+}$ buffer is three times the value in $\mathrm{Mg}^{2+}$ buffer, and is close to unity. Consequently, the interest in the use of boronic acid chemistries to capture rRNA for hybridization analysis is warranted.

Also examined was the selective capture of RNA through single-stranded portions in which bases are exposed to selective adsorptive interactions, with the idea that double-stranded DNA and non-nucleic acid contaminants would not be captured by such interactions. Results indicated that, in agreement with our working hypothesis that base nitrogen heterocycles could mediate an interaction with immobilized (chelated) metals, RNA adsorption is favored over that of DNA. Results are being extended through the work on gentle elution, compatible with direct introduction of the semi-purified RNA samples into a chip-based probe assay, ideally as the next step in a closed system.

Finally, phosphorimager storage plate technology was used to test novel purification methods in comparison with existing standard techniques such as the widely-used Tsai method (Figure 1-6). In addition to being spacecraft-compatible, our methods may find spin-off application on Earth because of their potentially greater convenience. Most recently, the use of nucleic acid conformation-modifying compaction agents was explored to facilitate purification by adsorption and by formation of flocs large enough to be separated from RNA by simple coarse filtration, or lowspeed centrifugation (Figures 1-7 and 1-8). 


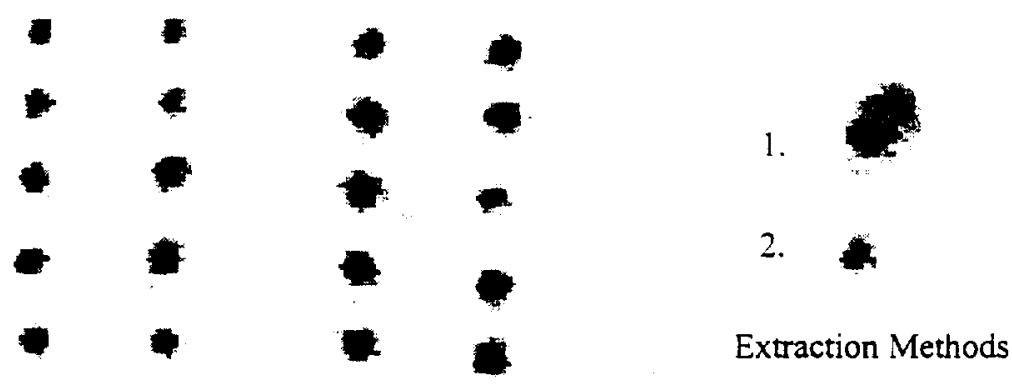

Reproducibility Standards

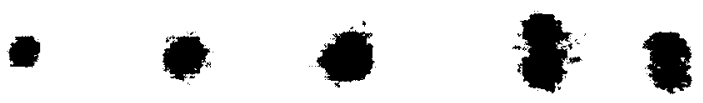

5S rRNA Standards

PSL of rRNA purifications between two differing extraction method protocols (far right). Standard controls with known concentrations (bottom).

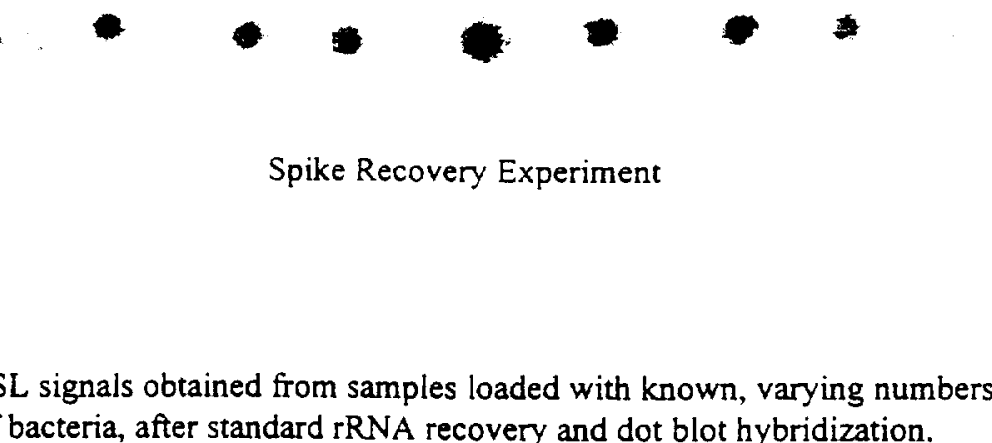
of bacteria, after standard $r R N A$ recovery and dot blot hybridization.

Figure 1-6 
Spermidine enhancement of Salmon Sperm DNA adsorption to the anionexchanger Q sepharose in $10 \mathrm{mM}$ Tris with $75 \mathrm{mM} \mathrm{NaCl} @ \mathrm{pH} 8.0$

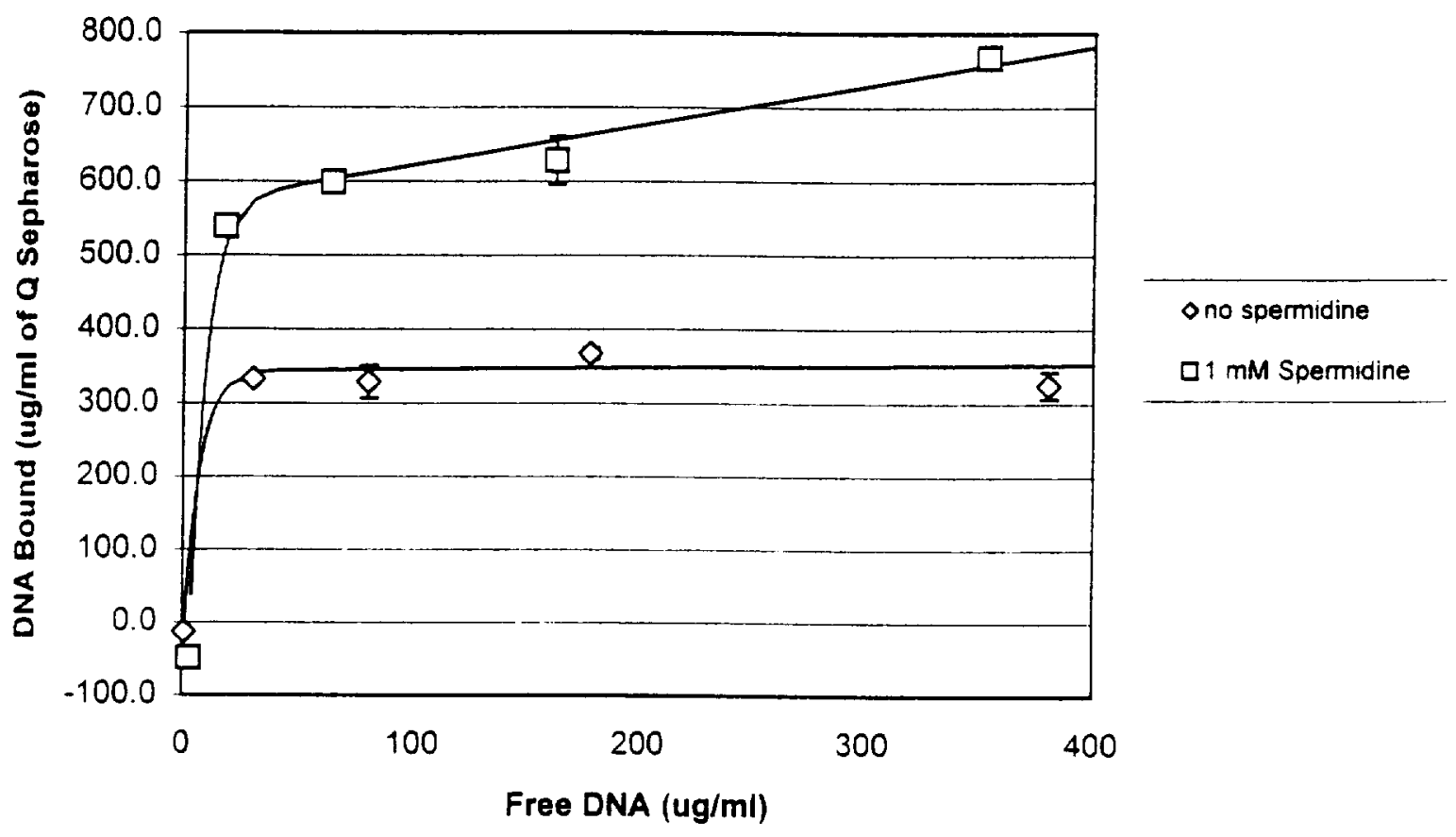

Salmon Sperm DNA (300 ug/ml) precipitation by higher concentrations of spermidine in $10 \mathrm{mM}$ Tris with $75 \mathrm{mM} \mathrm{NaCl} @ \mathrm{pH} 8.0$

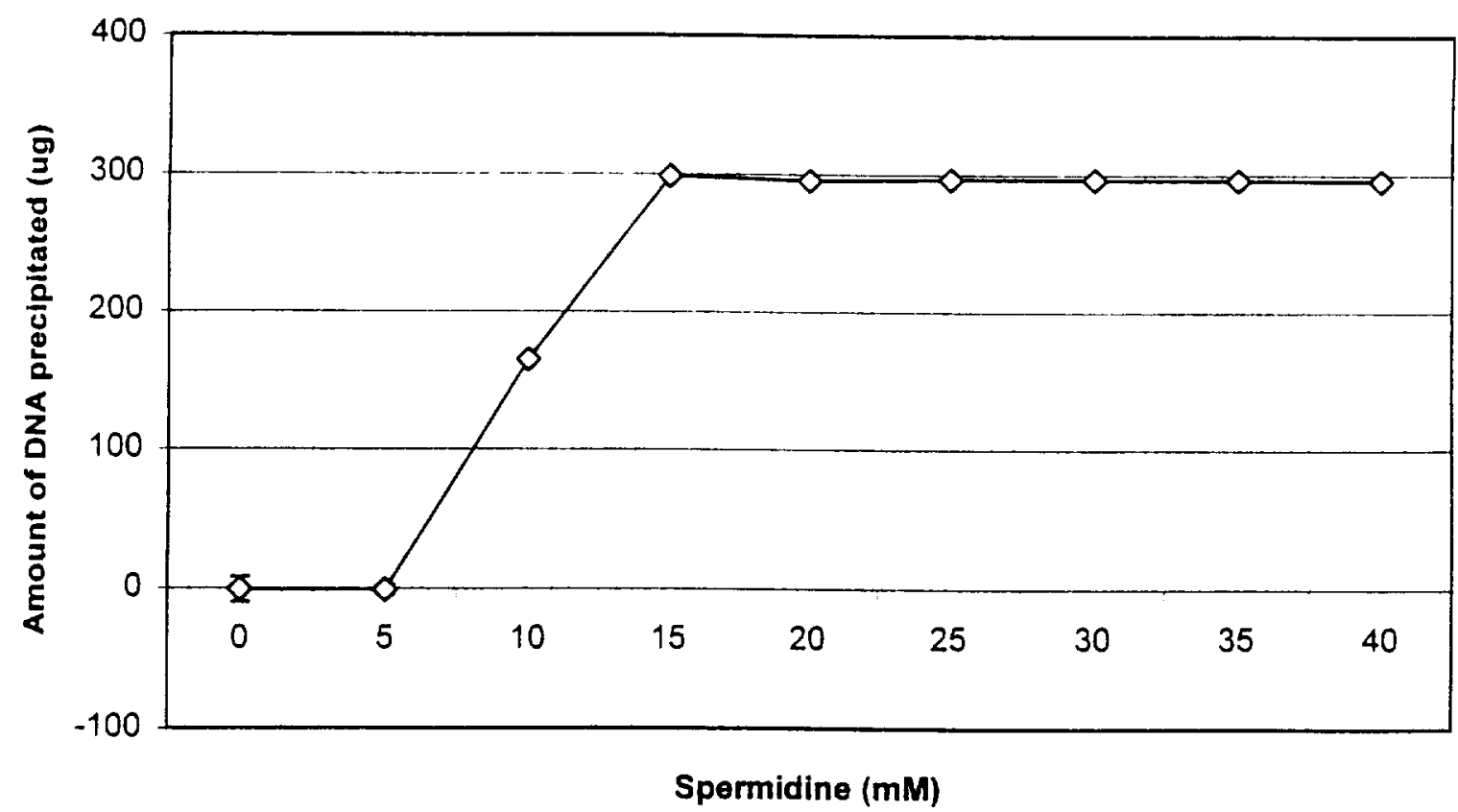

Figure 1-7 
Selective Precipitation of Salmon Sperm DNA from mixtures with Bakers

Yeast RNA (40 ug total nucleic acid in $\mathbf{5 0 0}$ ul)

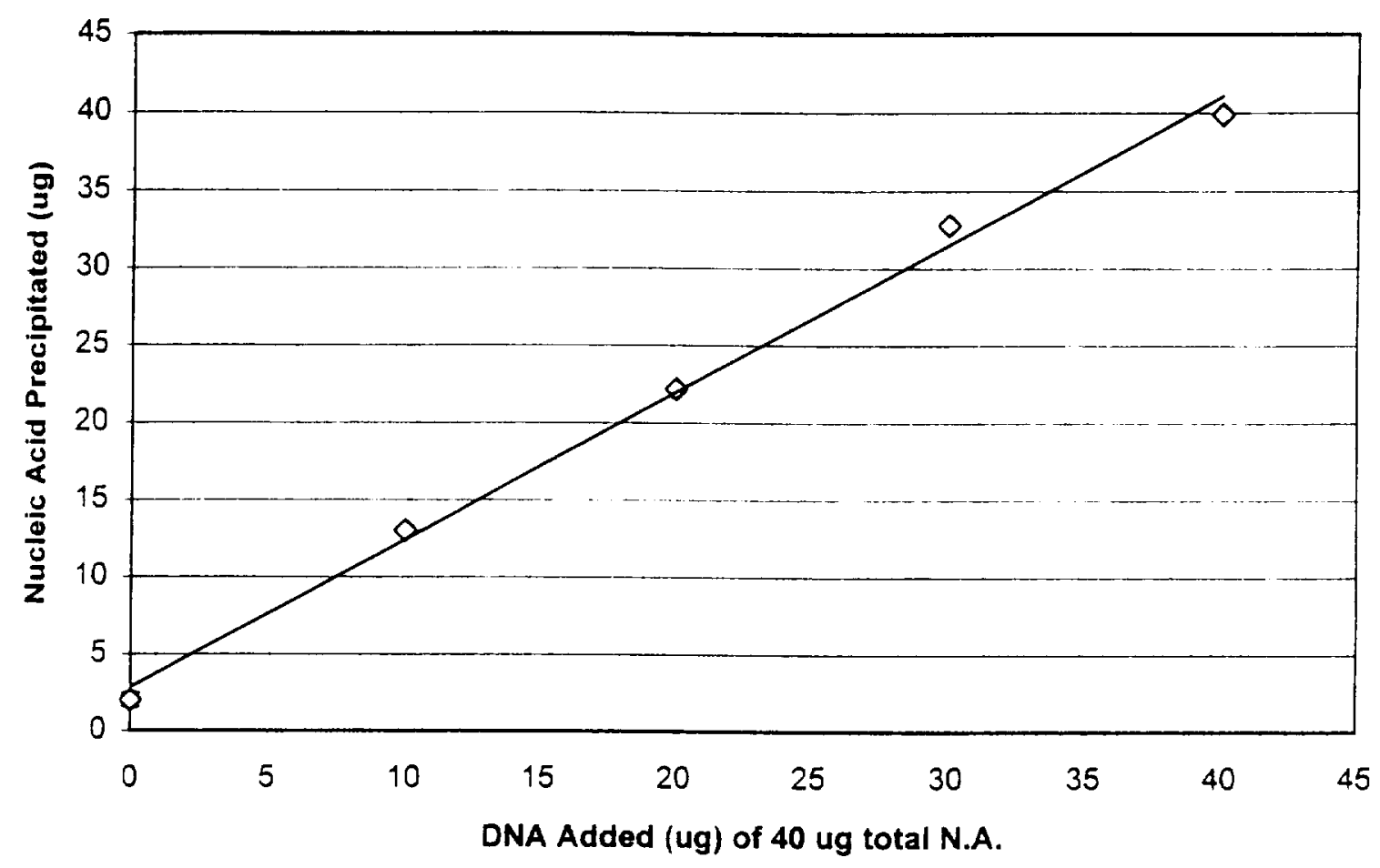

Figure 1-8 


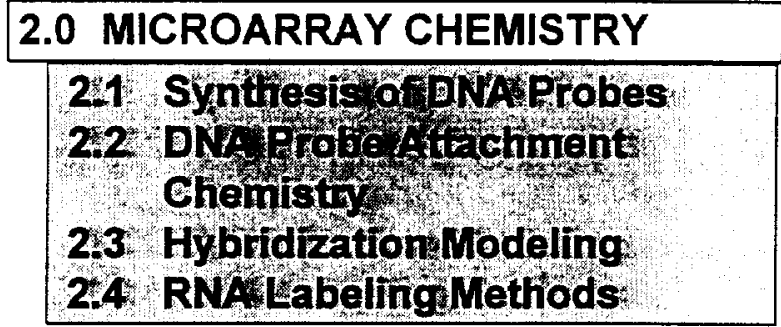

\subsection{Synthesis of DNA Probes}

A large number of oligonucleotide (short DNA) probes were synthesized with a variety of chemical modifications to serve as $16 \mathrm{~S}$ rRNA capture sequences. For modeling studies in the microtiter well format, these probe molecules were synthesized with a terminal biotin group which allowed easy and quantitative coupling to streptavidin derivatized surfaces. In some cases, probes of the same sequence were synthesized as the 2'-Omethyl derivative to compare binding efficiency and specificity. These 2'-Omethyl probes were found to have a somewhat greater affinity for rRNA capture, but at a significant loss of specificity, and were therefore terminated as candidate probe molecules.

Probes were also synthesized with a terminal $\mathrm{NH}_{2}$ group to allow chemical coupling to epoxide-derivatized glass and other candidate surfaces (such as succinic anhydride activated plastic) which would be compatible with microarray fabrication and proximal CCD imaging. The robotic deposition of these $\mathrm{NH}_{2}$ modified probes under mildly basic conditions on epoxidederivatized glass surfaces was found to be both efficient and reproducible, and was therefore employed for all subsequent studies in the microarray format.
A separate class of probes used as solution phase detector probes were synthesized with a terminal digoxigenin group. These probes were found to be effective not only in providing a detectable label on unlabeled rRNA molecules, but also in facilitating target site unwinding and presentation to surface capture probes as discussed below in the hybridization modeling.

\subsection{DNA Probe Attachment Chemistry}

As mentioned previously, the two primary methods of tethering oligonucleotide probes to solid supports were by the strong streptavidin-biotin interaction in the microtiter well format and by covalent coupling of $\mathrm{NH}_{2}$ modified molecules on vapor deposited epoxysilane modified glass surfaces. A thorough analysis of probe densities was performed on both types of surfaces. In the case of the streptavidin surface, it was found that the streptavidin modification of wells reproducibly provided essentially a monolayer coverage, and that the probe density converged to a value dictated by the diameter of the streptavidin molecule $(\sim 50 \dot{A})$. The binding of biotinylated molecules to such a surface is stoichiometric and essentially irreversible in nature and yielded a density of $5 \times 10^{10}$ molecules $/ \mathrm{mm}^{2}$ under conditions where probe is provided in excess of binding sites.

A similar density of probes was obtained on the epoxide-derivatized glass surfaces when $\mathrm{NH}_{2}$ containing probes were chemically coupled under mildly basic conditions. In contrast to the streptavidin surface, this chemical coupling is not stoichiometric in nature and requires the addition of 
somewhat higher molar amounts of probe to drive the reaction. This does not require a significant expenditure of probes, since, in general, these probes are deposited robotically in a microarray format in picoliter to nanoliter volumes.

A significant advantage of the epoxide surfaces is the fact that the monolayer provides reactive epoxides which are $5-7$ $\AA$ on center. Since the probe molecules are relatively large and highly negatively charged polyanions, their spacing under ordinary coupling conditions converges to a value of about $50 \AA$ on center due to steric and electrostatic considerations. The importance of this observation is that a large number of epoxides are unused and are available for secondary surface modifications with $\mathrm{NH}_{2}$ containing small molecules which may have attractive properties with regard to the enhancement of hybridization of $16 \mathrm{~S}$ rRNA target molecules. Preliminary results have demonstrated that such modifications are indeed possible, and represent an exciting possibility for the generation of second generation type microbial arrays.

\subsection{Hybridization Modeling}

A large effort has been made to identify parameters affecting the binding of the relatively large $16 \mathrm{~S}$ rRNA molecule to surface immobilized probes. These studies have been performed primarily in the streptavidin modified microtiter well format using chemiluminescent detection of bound molecules. The probes used in these studies have included sequences provided by the University of Houston group as well as some designed by the Baylor group.
Targets have included $E$. coli and Vibrio intact $16 \mathrm{~S}$ molecules, derivatives of these molecules generated by RT-PCR and synthetic targets representing various target sites of interest. Both equilibrium and kinetic data have been acquired under an extremely large set of experimental conditions.

By far, the most significant finding to emerge from these studies is the fact that the secondary structure adopted by the $16 \mathrm{~S}$ rRNA molecule in most ordinary hybridization solutions profoundly affects the outcome of surface binding. Although the secondary structure adopted by the $16 \mathrm{~S}$ molecule under biological conditions has been well documented, this structure is dependent on the presence of the cellular ionic environment as well as the presence of many ancillary $16 \mathrm{~S}$ associated proteins. Thus, this structure does not allow a priori knowledge of binding site availability in hybridization buffers lacking these factors. Research indicated that the inclusion of a solution state detector probe which was positioned to bind immediately adjacent to the capture probe could eliminate the apparent secondary structure effect in the target molecule. This effect is most likely due to a general unwinding or denaturation of the target molecule in the region of interest. The outcome of the use of such proximal detector or "chaperone" solution probes is illustrated below. 
A.

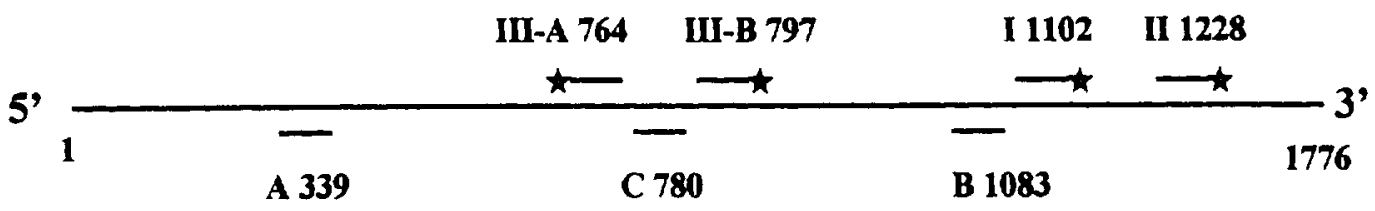

B.

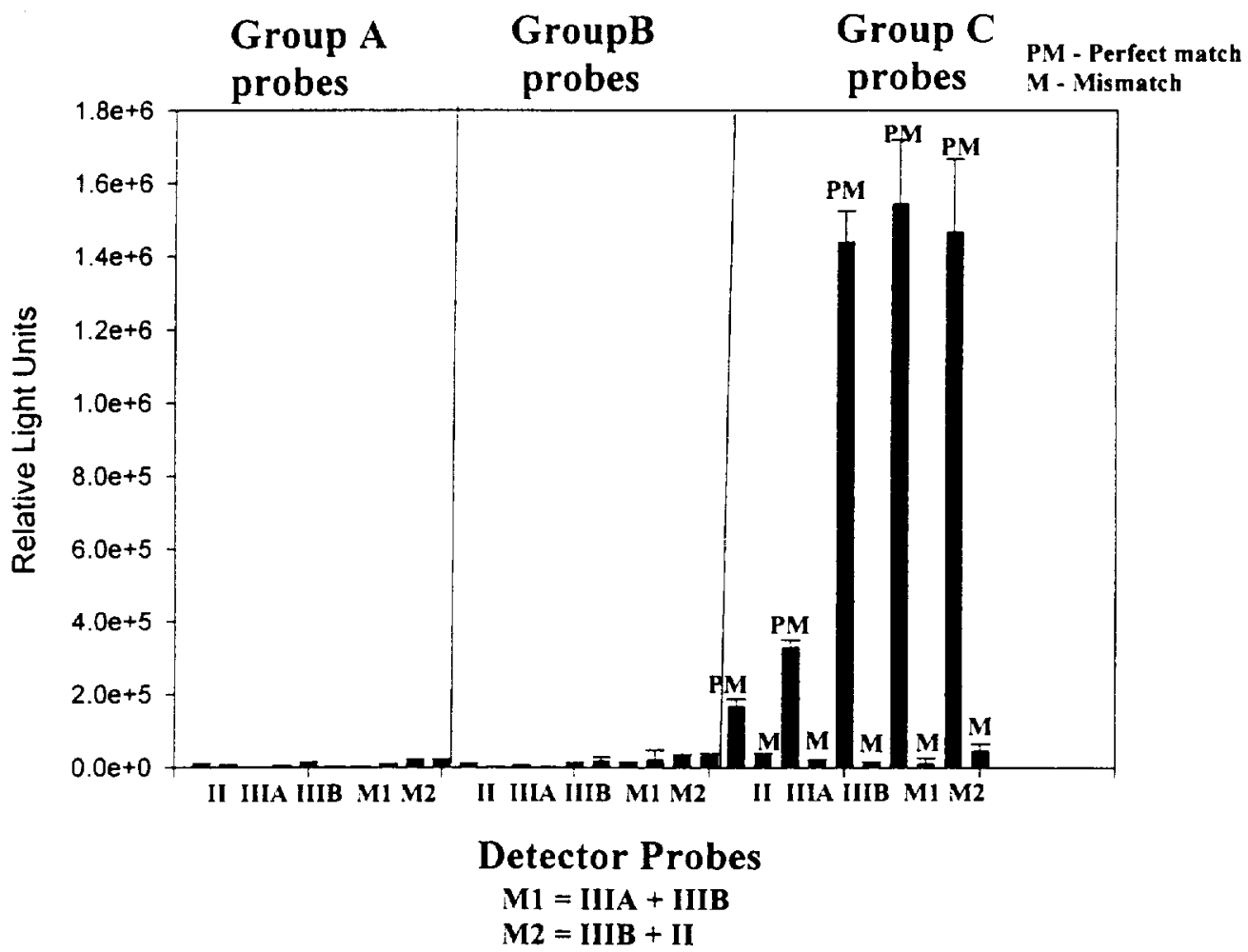

Figure 2-1. Proximal detector probe effect.

In Figure 2-1 A the position of capture and detector probes is shown (detectors above and capture probes below). The sequence of these probes has been previously reported in the July 1997 progress report. Figure 2-1 $B$ shows the result of binding experiments performed with capture probes $\mathrm{A}, \mathrm{B}$, and $\mathrm{C}$ and detectors II and III. As can be seen from the graph, the strongest hybridization signals are obtained with group $\mathrm{C}$ probes and the proximal detectors III-A and III-B. In contrast, Group A and Group B probes do not yield appreciable signal with these detectors or with detector II. These results provide further evidence of the effect of secondary structure on $16 \mathrm{~S}$ target binding and the utility of proximally positioned detector probes in overcoming this constraint. Although detector probe I was not synthesized, our prediction is that it 
would provide adequate signal with capture probe $B$ (with which it is proximal), and not with probes $A$ and $C$.

Given these constraints of the secondary structure of large target molecules, investigations are aimed at determining strategies for the hybridization of target molecules in ultra low ionic strength buffers. The use of such buffers would preclude the formation of significant structure of target molecules in solution. In order to provide the requisite screening for capture probe - target phosphate backbone repulsion, surfaces which may be induced to accumulate a positive charge are being tested. In one such scenario, probes are being deposited on a background of a small histidine containing peptide $\left(\mathrm{His}_{2} \mathrm{Glu}\right)$ whose charge may be modulated from +1 to -1 in the $\mathrm{pH}$ range of $5-8$ (the $\mathrm{pK}$ of histidine is 6.5). Preliminary evidence suggest that target molecules may be bound by specific duplex formation in very low ionic strength buffers when this type of surface is positively charged $(\mathrm{pH} \mathrm{5)}$. By elevating the $\mathrm{pH}$ to $7-8$ this surface can also contribute to the stringency of hybridization by accumulating a net negative charge. In addition, modified detector probes are being designed which contain small cationic peptides to allow binding of the detector in the same low ionic strength hybridization buffer. In this case, a single detector (for instance, complementary to the bacterial universal probe sequence) may be used for all bacterial $16 \mathrm{~S}$ species.

\subsection{RNA Labeling Methods}

Excellent results may be obtained using an enzyme-linked fluorescent assay (ELF, Molecular Probes) coupled with a proximal CCD detector. In this type of assay, either biotin or digoxigenin may be used as a recognition hapten for the target or detector molecule. Using streptavidin or antidigoxigenin conjugated alkaline phosphatase, the ELF substrate is cleaved to yield a fluorescent insoluble precipitate which accumulates at the sites of probe addresses which contain bound target molecules. This fluorescent precipitate is stable, does not bleach easily and has excellent spectral properties with regard to the CCD detector (excitation - $337 \mathrm{~nm}$, emission - $542 \mathrm{~nm}$ ). Using the signal amplification inherent in this type of enzymatic assay, $16 \mathrm{~S}$ rRNA target molecules bearing a single digoxigeninlabeled detector have been detected on microarrays at concentrations in the $10^{-13} \mathrm{M}$ range in a volume of $25 \mu \mathrm{l}$. In addition, the use of these enzyme conjugate assay schemes allow for the development of other types of substrate development (such as color), which may be of practical importance in limited equipment environments such as in space. 


\subsection{INSTRUMENTATION \\ 3.1. Microarray Pfinter \\ 3.2 Microarray Imager}

During the course of the program, a new capillary microarray fabrication method was developed and an existing CCD microarray imager was refined as described below. Both systems are amenable to miniaturized, high throughput operation. Specifically the dispensing system is capable of printing a DNA microarray per second, whereas the CCD-based imaging system provides quantitative detection and imaging within a few seconds.

\subsection{Microarray Printer}

A printer was developed for fabricating DNA microarrays utilizing capillary tubing to dispense extremely small amounts of DNA probe solution $(50 \mathrm{pL}, 50 \mu \mathrm{m}$ spot diameter) onto the interior bottom surface of 96 well microtiter plates, or onto microscope slides as illustrated in Figure 31. As shown, a storage vessel which contains the appropriate solutions is pressurized momentarily in order to prime the tubes to initiate the capillary dispensing action. Upon contact with the microtiter plate bottom, the capillary tubes simultaneously deliver small volumes of the DNA solutions at precise locations controlled by the spatial arrangement of the bundled capillaries.

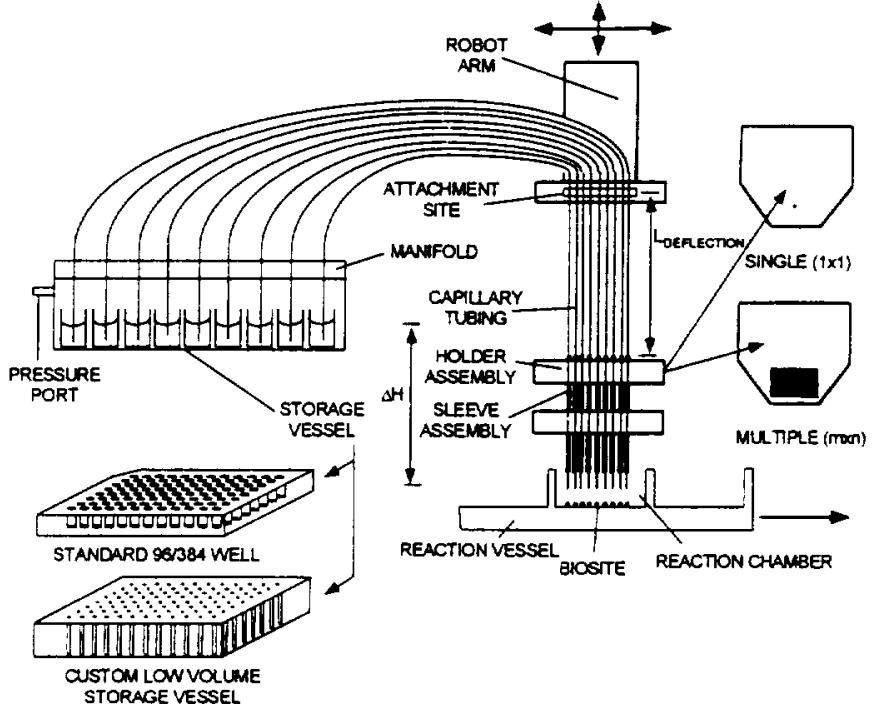

Figure 3-1. Biosite deposition system using multiple capillaries.

In the low volume manufacturing prototype shown in Figure 3-2, 190 micron outer diameter capillaries are threaded through an attachment site at the top of the printing fixture. The tubes extend down from the attachment site through an area allowing the capillaries to flex during printing. Below the flex region the capillaries are threaded through a set of fused silica sleeves held in a grid pattern by the aluminum holder assemblies.

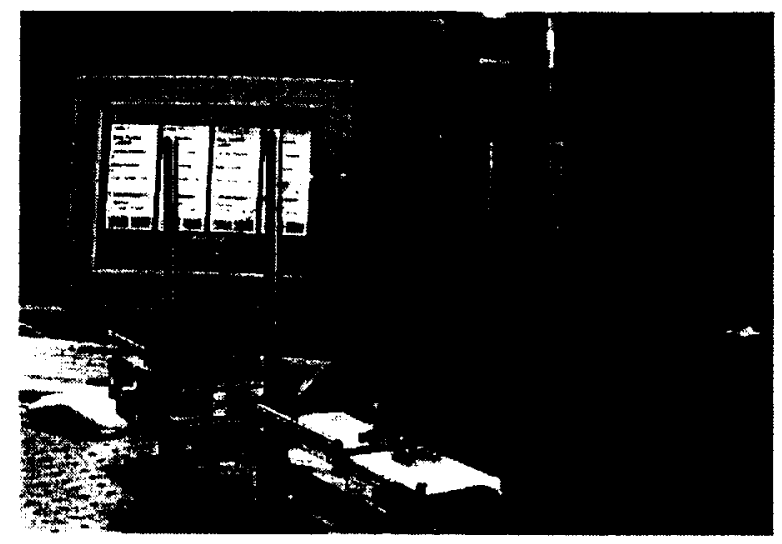

Figure 3-2. Prototype microarray manufacturing system. 
The microarray printer proved to be an extremely efficient instrument (1 array/ second print rate) for fabricating medium density microarrays $\left(10-1,000\right.$ probes $\left./ \mathrm{cm}^{2}\right)$. Moreover, Genometrix subsequently built a 4-head version of the printer with internal funds for high throughput commercial fabrication of microarrays within a class 1,000 clean room. The manufacturing capacity is estimated at one million microarrays per year.

\subsection{Microarray CCD Imager}

The heart of the microarray imaging instrument is the highly sensitive proximity (lensless) CCD imaging technology which provides high throughput detection and imaging of molecules labeled with chemiluminescent or fluorescent reporter groups.

As shown in Figure 3-3, a labeled molecular sample such as a DNA microarray is placed in direct proximity to the CCD sensor. Photoelectrons from the labeled sample are collected and quantified by the instrument within seconds.

The number of photoelectrons generated at each pixel is directly proportional to the number of labeled molecules in such proximity. Consequently, molecular detection and imaging can be quantitatively provided in an automated digital format.

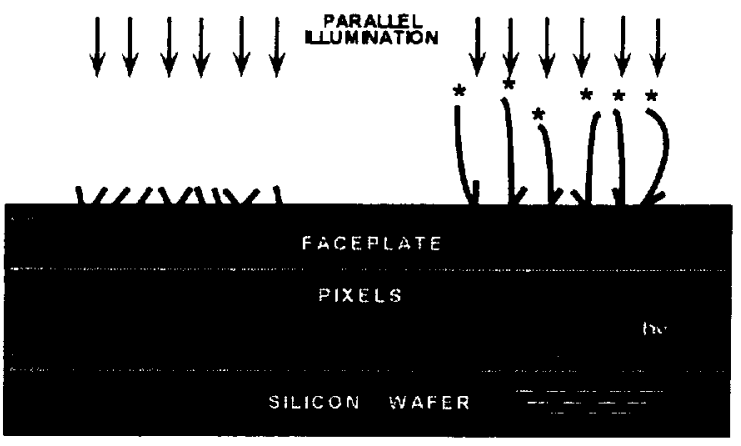

Figure 3-3. CCD proximal detector schematic.

The PC-based CCD proximal detector/ imager shown in Figure $3-4$ is approximately 10 -fold more sensitive than conventional phosphorimagers and fluorimagers, and represents a triumph over numerous engineering challenges.

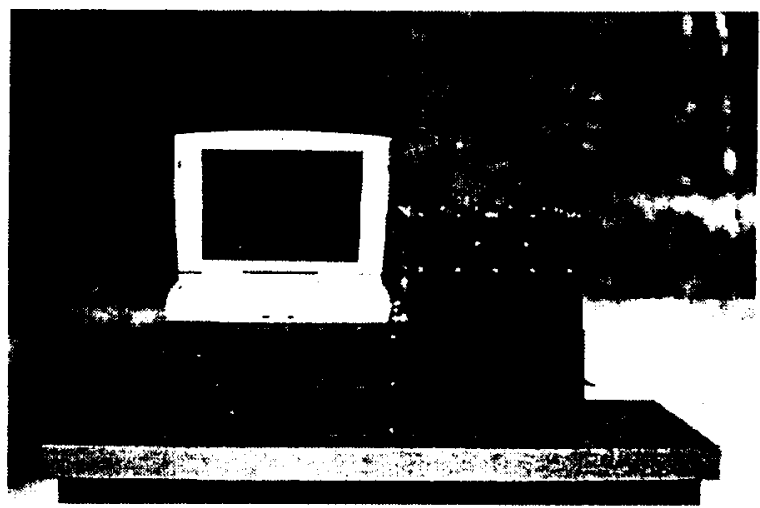

Figure 3-4. PC-based proximal CCD detector. 


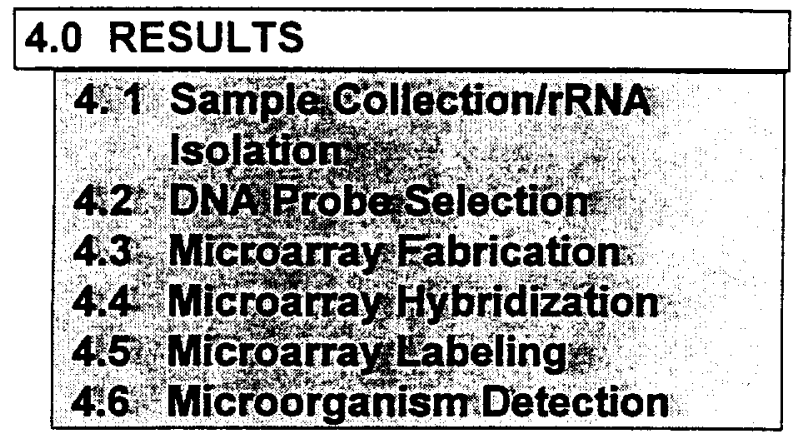

In addition to the developments arising from individual program components reported in the previous sections, results are also reported for the integrated microbial detection system tested on live waste water samples collected from the Lunar-Mars Life Support Test Project.

\subsection{Sample Collection/rRNA Isolation}

Environmental waste water samples were collected from the Lunar-Mars Life Support Test Project at JSC. Grab samples were obtained from three separate sample points from the Immobilized Cell Bioreactor System.

Sample point \#1 was taken from the Main Feed Tank (TK-Bio-01). Sample \#2 was obtained from the TFB Product Tank (TKBio-21) and finally sample point \#3 was obtained from the ICB Effluent Column. Due to time constraints, only rRNA samples from the Main Feed Tank were analyzed by microarray hybridizations. A schematic of the main feed tank is illustrated in Figure 4-1 below.

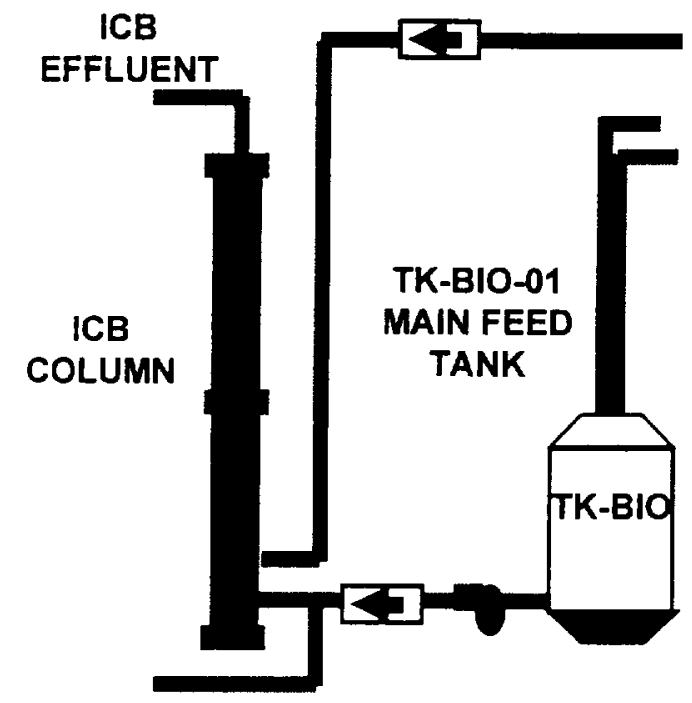

Figure 4-1. Lunar-Mars water treatment system.

Water samples $(250 \mathrm{~mL}$ each $)$ were centrifuged to pellet the solids and frozen at $-20^{\circ} \mathrm{C}$ until processed for rRNA isolation. All ribosomal RNA preparations were performed using Qiagen's RNeasy Total RNA Purification kit according to the manufacturer's instructions.

Total RNA was isolated from approximately $50 \mathrm{mg}$ of microbial cell paste or sample pellet. After purification, an agarose gel was run to confirm presence or absence and quality of rRNA isolated from the three environmental sample points. A photograph of the gel is shown in Figure 4-2 below. 


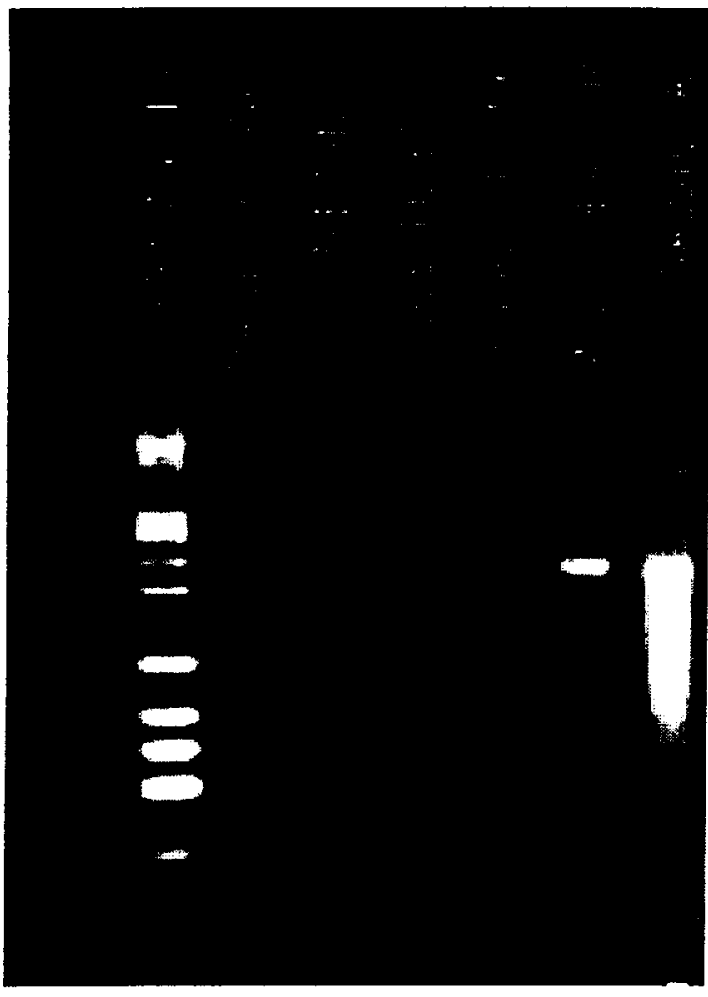

Figure 4-2. Ribosomal RNA isolated from various Lunar-Mars water treatment sample points as well as several known bacterial isolates.

\subsection{DNA Probe Selection}

Oligonucleotide sequences were designed by George Fox's Lab at the University of Houston. Microbial-specific sequences were chosen by computer alignment of rRNA sequences from an NCBI database. Alignment and probe design were carried out using GCG Software (Genetics Computer Group, Wisconsin Package 9.0).

Species-specific oligonucleotide capture sequences were synthesized using conventional automated DNA phosphoramidite chemistry and purified using HPLC.
Oligonucleotide capture and detectionchaperone sequences are outlined in Table 41 and Table $4-2$ respectively.

5' -ACTCCGGGTATTAGCCAGAAT 3 '

5'- GGCTGTATTAGAGCCAA 3'

5' -GGCTATATTAGAACCAA 3'

5'-GCCATCAATCTAGCAAGC 3'

5' -TATCCCACATCATCCAC 3'

5' -TCAATGAGCAAAGGTAT3'

5'-AGCCTCCTCCTCGCTTAAA 3'

5' -TGCCCTTCCTCCCAACTT 3'

5'-ATTAATCCACATCATCCAC 3'

5'-GAATCCCAACAACTAGTT 3'

5'-CTGCCTCCCGTAGGAG 3'

5' -AGGGTATCTAATCCTGTTT 3'

5'-GGGACTTAACCCAACA 3'

Table 4-1. Microbial microarray oligonucleotide capture sequences.

\section{5'-TTCTTCCGGTACCGTCAT 3'}

5'-TTCCGGTACCGTCATCCC 3' 5'-TTCCGGTACCGTCATCCC 3'

5' -TACTCACCCGTTCGCCAC 3'

5, -TTTCGCGTTGCATCGAAT 3'

5' -TGCTTCTTCTGCGGGTAAC 3'

5'- GCTTTACAACC(A/C)(A/T)A AGGCCT 3'

5'- AAAGTGCTTTACAATCCGAAGA3'

5' -AGGTT(C/T)TTCGCGTTGCAT 3'

5'- G(N)CCGT(A/G)T(C/T)TCA GT(N)CC 3'

5'-GTTTA(C/G)(N)GC(A/G)TG GACTA 3'

5'-TCAC(A/G)(A/G)CACGAG CTGACG 3'

Table 4-2. Microbial microarray oligonucleotide detector sequences. 
The standard hybridization format used throughout the experiments is illustrated in Figure 4-3.

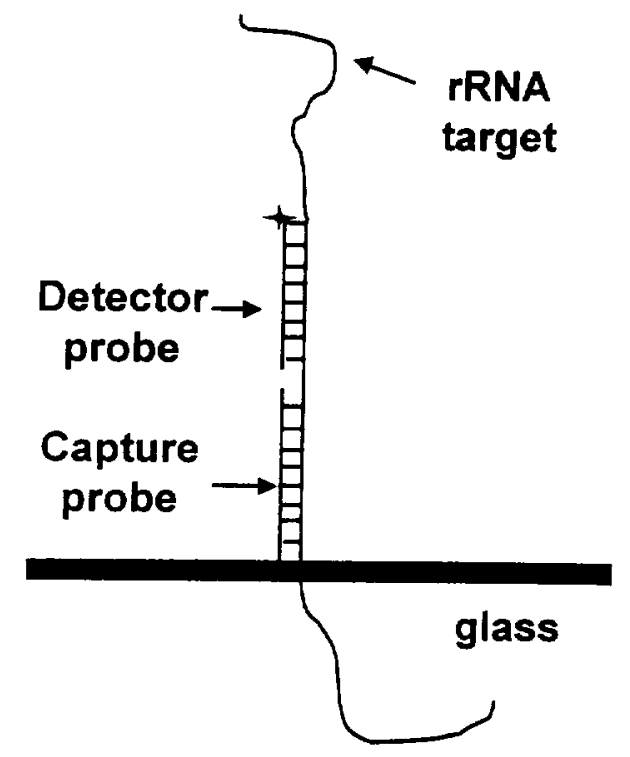

Figure 4-3 . Hybridization format.

Oligonucleotide capture sequences were printed on microslides to form a $4 \times 4$ microarray using the robotic capillary printing system. The four outside corners of the array were delineated with an immobilized biotin-labeled control marker which also serves as a detection reagent control spot. The array configuration is illustrated in Figure 4-4.

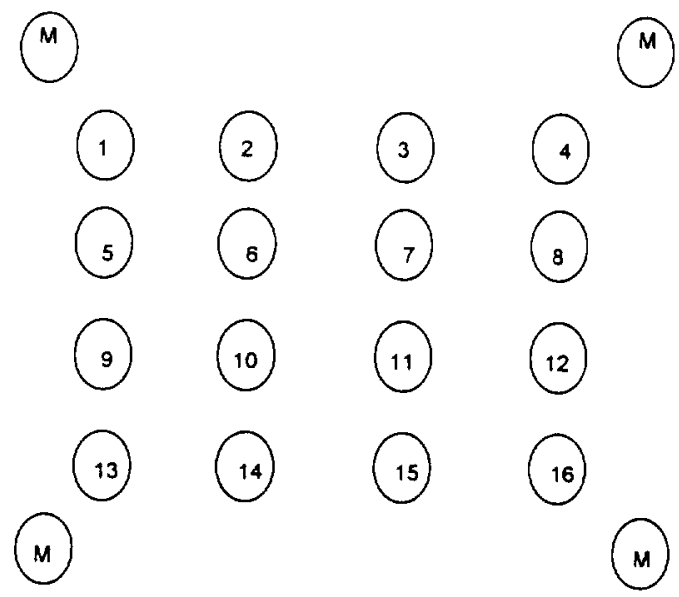

$\underline{\text { Key }}$

M-detection marker

1 -Blank

2 -Blank

3 -Pseudomonas

4 -Pan Probe (all bacteria)

5 -Ralstonia Picketti

6 -Staphylococcus 760

7 -Staphylococcus 692

8 -Staphylococcus 629

9 -Burkholderiae 823

10-Burkholderiae Pseudomallei

11-Burkholderiae Cepacia

12-Ralstonia Picketti 942

13-Acinetobacter

14-Escherichia coli

15-Burkholderiae Cepacia (MIR strain)

16-Burkholderiae/Neisseria

\subsection{Microarray Fabrication}

Glass microslides were purchased from Cell-Line Inc. per Genometrix specification (see Figure 4-5) and washed using an ultrasonic cleaner (Aquasonic Model 410T). Specifically, a formulated cleaning concentrate (Branson GP) was diluted 50:1 in warm tap water. The slides were immersed in the cleaning solution and sonicated for 5 minutes. Following sonication, the slides were rinsed in progressively more deionized and demineralized water dip tanks. The final water rinse was made in deionized and glass distilled water of the highest purity.

Following the water wash, the slides were briefly immersed in an acetone bath, followed by a methanol final rinse. The slides were oven dried at $45^{\circ} \mathrm{C}$ for 15 minutes and chemically derivitized by vacuum deposition of epoxysilane using a

Figure 4-4. Microbial microarray layout. 
carrier solvent in a conventional vacuum oven at $80^{\circ} \mathrm{C}$ for 16 hours (at $25^{\prime} \mathrm{Hg}$ ).

Next, the slides were removed from the oven and stored in a clean dry place until printing of capture sequences using the microarray printer.

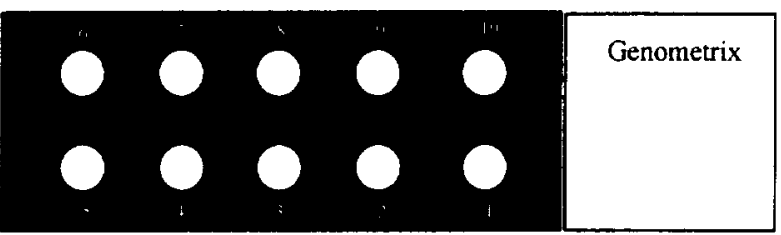

Figure 4-5. Teflon-coated glass microslides.

\subsection{Microarray Hybribization}

Microarray hybridizations on microslides were performed by a simple three step process as outlined below.

Step 1

Pre-hybridize each well in $100 \mathrm{uL}$ of prehyb solution ( $0.6 \times \mathrm{SSC} / 5 \mathrm{X}$ Denhardts) for 20 minutes at room temperature. The prehyb solution is removed with a pipetteman immediately followed by step 2 below.

Step 2

To fifty microliters of purified rRNA in 10 $\mathrm{mM}$ Tris- $\mathrm{HCl}$ (7.5) was added $32 \mathrm{uL} \mathrm{DEPC}$ $\mathrm{dH} 20$ and $10 \mathrm{uL}$ of $1 \mathrm{uM}$ detector oligo mix. Estimated rRNA target concentrations over each array is approximately $1 \times 10^{-8} \mathrm{M}$. The sample is heated for 3 minutes at $72^{\circ} \mathrm{C}$ and snap chilled on ice. The final hybridization mix is completed by adding 3 uL 20xSSC and $5 \mathrm{uL}$ of $100 \mathrm{X}$ Denhardts. A $20 \mathrm{uL}$ aliquot is added to each of three prehybridized microarray wells from Step \#1 above. Hybridizations are allowed to proceed for 90-120 minutes at room temperature.

Step 3

After the hybridization is complete, the hybridization solution is removed with a pipetteman, followed by three consecutive $100 \mathrm{uL}$ stringency washes at room temperature with $0.6 \mathrm{XSSC}+5 \mathrm{X}$ Denhardts.

\subsection{Microarray Labeling}

Microarray labeling proceeded immediately following the stringency washes. Each well was subjected to the following four step process.

Step 1

Each microarray well is rinsed once with $100 \mathrm{uL}$ of conjugate wash buffer ( $1 \times$ TBS $+0.1 \%$ Tween 20 ) for 30 seconds.

Step 2

The wash buffer is removed using a pipettman followed by incubating each well in $25 \mathrm{uL}$ of conjugate (1:1000 dilution of a streptavidin- alklaline phosphatase conjugate in wash buffer) for 45 minutes.

Step 3

After removal of the conjugate, each well is washed three additional times with $100 \mathrm{uL}$ of conjugate wash buffer.

Step 4

ELF $^{\mathrm{TM}}$ (Enzyme-linked substrate, Molecular Probes, Inc.) substrate is freshly prepared and $25 \mathrm{uL}$ is added to each well. Substrate development is allowed to proceed in a humidity chamber for 30 minutes at $37^{\circ} \mathrm{C}$. 


\subsection{Microorganism Detection}

Microarray detection results are shown in Figure 4-6. Each microbial rRNA sample $(100 \mathrm{uL})$ was hybridized to three identical but separate array wells to assess reproducibility.

The results of hybridizing $20 \mathrm{uL}$ of purified (Qiagen) rRNA isolated from Burkholderiae Cepacia species at a final concentration of $1 \times 10^{-8} \mathrm{M}$ is shown in Figure 4-6 (a). Clearly from the array image, positions 12 (Ralstonia Picketti 942) and 16 (Burkholderiae/Neisseria) provide strong signals which is due to sequence similarity among these species. However position 11 (Burkholderiae Cepacia) does not provide a positive signal in any of the images suggesting that the probe for Burkholderiae Cepacia lacks the desired specificity required for accurate detection.

Figure 4-6 (b) is an image of three arrays hybridized to Ralstonia Picketti rRNA. As expected, biosites 5 (Ralsonia Picketti) and 12 (Ralstonia Picketti 942) provide strong positive signals. Also, biosite 16 (Burkholderiae/Neisseria) indicates strong hybridization which is due to sequence similarity.

Finally, Figure 4-6 (c) is a hybridization performed with rRNA isolated from the Main Feed Tank (See Figure 4-1) waste water from the Lunar-Mars Life Support Test Project. The image clearly shows a strong hybridization signal from 3 (Pseudomonas) and 13 (Acinetobacter). Notice that the lesser intense hybridization signals at biosites $6,7,8$ collectively, represent probes for Staphylococcus. Hence the sample may also contain Staphylococcus due to the triplicate appearance of such hybridizations.
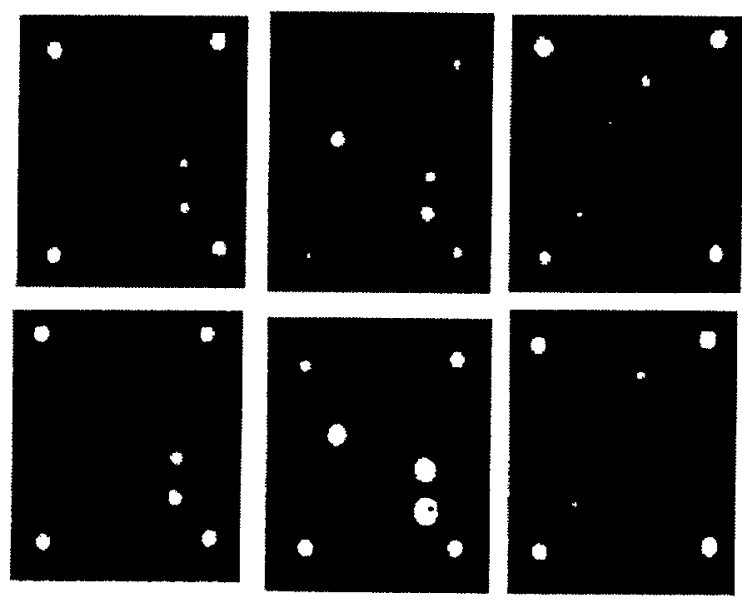

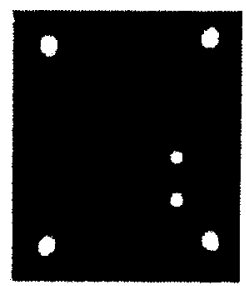

a

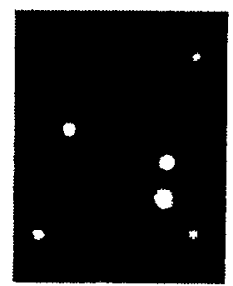

b

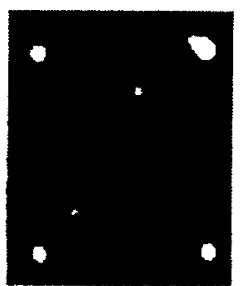

C
Figure 4-6. Microbial microarray images. 


\subsection{REFERENCES}

Ackerman, S., Cool, B., and Furth, J. J. (1979). Removal of DNA from RNA by chromatography on acetylated $\mathrm{N}-\left[\mathrm{N}^{\prime}-(\mathrm{m}-\right.$ dihydroxylborylphenyl)succinamyl]aminoet hyl cellulose, Analytical Biochemistry 100: 174-178.

Alm, E. W., Oerther, D. B., Larsen, N., Stahl, D. A., and Raskin, L., (1996). The oligonucleotide probe database, Applied and Environmental Microbiology, 62: $3557-$ 3559.

Amann, R. I., Ludwig, W., and Schleifer, K. H. (1995). Phylogenetic identification and in situ detection of individual microbial cells without cultivation,. Microbiological Reviews 59: 143-169.

Benes, M. J., Stambergova, A. and Scouten, W. H. (1993). Affinity chromatography with immobilized benzeneboronates, in Molecular Interactions in Bioseparations (That T. Ngo ed.) Plenum Press, NY, pg. 313-322.

Bergold, A., and Scouten, W. H. (1983). Boronate chromatography, in: Solid Phase Biochemistry: Analytical and Synthetic Aspects (W. H. Scouten ed.), John Wiley \& Sons, pg. 149-187.

Bouriotis, V., Galpin, I., and Dean, P. D. G. (1981). Application of immobilized phenylboronic acids as supports for groupspecific ligands in the affinity chromatography of enzymes, Journal of Chromatography 210: 267-278.
Fulton, S. (1981). Boronate Ligands in Biochemical Separations, Amicon Corporation, Danvers, MA, Amicon Publication No. 507.

Jurtshuk, R. J., Blick, M., Bresser, J., Fox, G. E., and Jurtshuk, P. Jr., (1992). Rapid in situ hybridization technique using $16 \mathrm{~S}$ rRNA segments for detecting and differentiating the closely related Grampositive organisms Bacillus polymyxa and Bacillus macerans, Applied Environmental Microbiology 58: 2571-2578.

Liu , X. C. and Scouten, W. H. (1994). New ligands for boronate affinity chromatograohy, Journal of Chromatography A 687: 61-69.

Liu, X. C., Hubbard, J. L. and Scouten, W. H. (1995). Synthesis and structural investigation of two potential boronate affinity chromatography ligands, catechol [2-(diethylamino) carbonyl, 4-methyl] phenylboronate, Journal of Organometallic Chemistry 493: 91-94.

McCutchan, T. F., Gilham, P. T., and Soll, C. (1975). An improved method for the purification of $t R N A$ by chromatography on dihydroxyboryl substituted cellulose, Nucleic Acids Research 2: 853-864.

Moore, E. C., Peterson, D., Yang, L. Y., Yeung, C. Y., and Neff, N. F. (1974). Separation of ribonucleotides and deoxyribonucleotides on columns of boronate covalently linked to cellulose. Application of the assay of ribonucleoside diphosphate reductase, Biochemistry 13: 2904-2907. 
Pace, B., and Pace, N. R. (1980). The chromatography of RNA and oligonucleotides on boronate-substituted agarose and polyacrylamide, Analytical Biochemistry 107: 128-135.

Tsai, Y. L, Park, M. J., and Olson, B. H. (1991) Rapid method for direct extraction of mRNA from seeded soils, Applied and Environmental Microbiology 57: 765-768. 


\subsection{CONCLUSIONS}

The utility of a novel microarray-based microbial analyzer was demonstrated by the rapid detection, imaging, and identification of a mixture of microorganisms found in a waste water sample from the Lunar-Mars Life Support Test Project through the synergistic combination of:

- judicious RNA probe selection via algorithms developed by University of Houston scientists

- tuned surface chemistries developed by Baylor College of Medicine scientists to facilitate hybridization of rRNA targets to DNA probes under very low salt conditions, thereby minimizing secondary structure

- integration of the microarray printing and detection/imaging instrumentation by Genometrix to complete the quantitative analysis of microorganism mixtures.
Since the presented DNA array-based approach is fast ( five minute hybridization with new active surface chemistries followed by 15 seconds for detection, imaging, quantitation, and data storage) and amenable to miniaturization, the results demonstrate the favorable potential for rapid microbial monitoring of air and water supplies.

However, additional issues must be addressed before employment in a space environment, such as safe and efficient methods for collecting and extracting RNA from potentially contaminating microbes. Initial results on the boronate affinity capture methods presented for isolating RNA appear promising. This method offers greater convenience and avoids toxic substances such as phenol and ethidium bromide used on conventional RNA isolation protocols. And finally, all instrumentation components ranging from sample preparation to detection must be integrated into a miniaturized, modular system for ultimate deployment in a space environment. 